\title{
PREVALÊNCIA DE INFECÇÃO URINÁRIA E DE Actinomyces suis EM PORCAS GESTANTES E SUA CORRELAÇÃO COM ALGUNS PARÂMETROS FÍSICOS E QUÍMICOS DA URINA (Prevalence of urinary tract infections and of Actinomyces suis in urine from pregnant sows. Correlation with some urine's physical and chemical parameters)
}

\author{
ALBERTON, G.C. ${ }^{1}$; WERNER, P.R. ${ }^{2}$; SOBESTIANSKY, J. ${ }^{3}$; COSTA, O.D. ${ }^{4}$; BARIONI JÚNIOR, W. ${ }^{4}$
}

\author{
${ }^{1}$ Departamento de Medicina Veterinária - Universidade Federal do Paraná; \\ ${ }^{2}$ Universidade Paranaense/Universidade Federal do Paraná; \\ ${ }^{3}$ Universidade Federal de Goiás; \\ ${ }^{4}$ Centro Nacional de Pesquisa de Suínos e Aves - EMBRAPA.
}

RESUMO - O presente trabalho teve como objetivo determinar a prevalência de infecção urinária e da bactéria Actinomyces suis na urina de 1745 porcas gestantes da região Sul do Brasil e correlacionar essa prevalência com parâmetros físicos e químicos da urina. A prevalência de infecção urinária e de $A$. suis foi de $28,31 \%$ e $20,63 \%$, respectivamente. Observou-se correlação negativa entre infecção urinária e $A$. suis, ou seja, as porcas que apresentaram infecção urinária tinham menor prevalência de $A$. suis $(13,67 \%)$ do que as que não a apresentaram $(23,12 \%)$. Da mesma forma, as porcas portadoras de $A$. suis, tinham menor prevalência de infecção urinária $(17,43 \%)$ do que as não portadoras $(28,62 \%)$. Apenas $3,60 \%$ das porcas examinadas eram positivas para infecção urinária e A. suis simultaneamente. A cor predominante da urina foi a amarelo claro, tanto para as porcas portadoras ou não portadoras de infecção urinária ou de $A$. suis. Constatou-se a presença de turbidez em $83,15 \%$ das amostras, sendo que em $96,18 \%$ das amostras turvas observou-se a presença de cristais. Finalmente, a cor, aspecto, densidade, $\mathrm{pH}$ e presença de cristais, foram considerados como parâmetros sem valor para o diagnóstico presuntivo de infecção urinária em porcas gestantes.

Palavras chave: suínos, infecção urinária, Actinomyces suis, Escherichia coli.

ABSTRACT - A survey has been carried out in urine samples from 1745 pregnant sows from Southern Brazil, in regard to the prevalence of urinary infections and of Actinomyces suis and its correlation with some of the urine physical and chemical parameters. Prevalence of urinary infections was of $28.31 \%$ and that of $A$. suis, $20.63 \%$. However, a negative correlation has been found between the incidence of urinary infection and the presence of $A$. suis, the prevalence of the latter being lower in sows which are positive for urinary infections $(13.67 \%)$ than in those without urinary infection $(23.12 \%)$. At the same time, sows positive for $A$. suis display a lesser number of urinary infection $(17.43 \%)$ than those negative for the bacteria $(28.62 \%)$. Only in $3.60 \%$ of the sows, urinary infection and $A$. suis occurred simultaneously. Due to the presence of crystals, turbidity was frequently observed in sow's urine (83.15\%). Crystals were present in $96.18 \%$ of sow's turbid urine samples. Furthermore, color, turbidity, density, $\mathrm{pH}$ and the presence of crystals were not considered of value for the presumptive diagnosis of urinary tract infections in pregnant sows.

Key word: swine, urinary infection, Actinomyces suis, Escherichia coli.

\section{Introdução}

As infecções urinárias em suínos afetam principalmente as porcas causando uma acentuada redução nos índices de produtividade das granjas. Em estudos epidemiológicos realizados na Alemanha por BERNER (1978), na França por MADEC e DAVID (1984); em Portugal por PERESTRELO e PERESTRELO (1988) e no

Correspondência para: Geraldo Alberton - Departamento de Medicina Veterinária - Universidade Federal do Paraná, Rua dos Funcionários, 1540, CEP 80035-050, Curitiba-PR-Brasil. E-mail: alberton@agrarias.ufpr.br.
Brasil por SOBESTIANSKY et al. (1995), a prevalência de infecção urinária em porcas foi de aproximadamente $30 \%$ em granjas comerciais.

Estas infecções são de origem multifatorial, quando se aliam enterobactérias de poder patogênico facultativo com práticas de manejo que predispõe os animais à estas doenças. Entre os microorganismos que causam esta doença, destaca-se a Escherichia coli (SOBESTIANSKY et al., 1999). De acordo com BERNER (1980), mais de $50 \%$ dos casos de infecção urinária são causados por esta bactéria. Em um trabalho realizado por MADEC e DAVID (1983) de 350 porcas com 
infecção urinária, a $E$. coli foi isolada da urina de $58 \%$ das fêmeas. Estas infecções normalmente restringem-se à bexiga das porcas e são altamente freqüentes. Outra bactéria que pode participar da patogênese da infecção urinária é o Actinomyces suis, microorganismo cujo habitat natural é o prepúcio dos cachaços, sendo transmitido às porcas por ocasião da cobertura. Uma vez introduzido no trato urogenital, o $A$. suis pode, por via ascendente, atingir a bexiga e os rins onde, na presença de fatores predisponentes, pode provocar cistite ou pielonefrite (WENDT et al., 1993b). A maioria dos machos da espécie suína, com idade de seis meses ou mais, albergam esta bactéria no divertículo prepucial, sendo que a colonização deste órgão pode acontecer quando os leitões estão com apenas poucas semanas de idade (JONES, 1992). As infecções urinárias com participação do $A$. suis são mais graves e podem causar a morte das porcas, contudo, são pouco freqüentes (DEE, 1991).

Dentre as práticas que predispõem as porcas à infecção urinária destacam-se: ingestão de volume insuficiente de água; água de má qualidade; má higiene das instalações e contato prolongado da vulva com o piso; pouca motilidade das porcas; porcas idosas; traumas e estresse (SOBESTIANSKY et al., 1999).

As infecções urinárias nas porcas geralmente evoluem sem manifestação de sinais clínicos evidentes, passando muitas vezes despercebidas pelo produtor e pelo Médico Veterinário. Assim, há necessidade de se utilizar métodos diagnósticos simples e confiáveis que permitam identificar as infecções urinárias antes que se tornem um problema grave dentro da granja (SOBESTIANSKY e WENDT, 1993). Entre os métodos de diagnóstico de infecção urinária, tem sido recomendado o uso de tiras reagentes para exames químicos da urina. Recomenda-se o uso de tiras reagentes que possibilitem a pesquisa de nitrito, sangue e proteína na urina e mensurem o $\mathrm{pH}$ urinário. $\mathrm{O}$ uso de tiras reagentes para o diagnóstico das infecções urinárias tem se tornado muito freqüente, pela sua praticidade e confiabilidade (GARCIA-NAVARRO,1996), e pela possibilidade de ser realizado na própria granja (SOBESTIANSKY e WENDT, 1993).

O presente trabalho teve como objetivos: (a) determinar a prevalência de infecções urinárias em porcas criadas em confinamento ou criadas ao ar livre, em granjas da região Sul do Brasil; (b) determinar a prevalência da bactéria Actinomyces suis naquelas porcas, tentando elucidar a importância da bactéria no desenvolvimento da infecção urinária; e (c) estudar alguns parâmetros físicos e químicos da urina de porcas tentando correlacioná-los à presença de infecção urinária e $A$. suis.

\section{Material e Métodos}

Foram examinadas amostras de urina de 1745 porcas gestantes escolhidas ao acaso, de 25 granjas de suínos da região Sul do Brasil. Das granjas estudadas, sete adotavam o sistema intensivo de suínos criados ao ar livre (SISCAL) e 18 mantinham seus animais no sistema intensivo de suínos criados confinados (SISCON).

As colheitas de urina eram realizadas durante micção espontânea antes do amanhecer e do primeiro arraçoamento da manhã. Após a colheita, as amostras foram remetidas para o laboratório, onde foram submetidas a exames físico, químico, de sedimento e imunofluorescência indireta para pesquisa de $A$. suis. Todas as análises foram realizadas no Centro Nacional de Pesquisa de Suínos e Aves - CNPSA/EMBRAPA, localizado em Concórdia - SC.

As características físicas analisadas foram: cor, aspecto, odor e a densidade. No quesito cor, as amostras foram classificadas em incolor, amarelo claro e amarelo escuro; no quesito aspecto, em límpidas e turvas e, no quesito odor, em característico e amoniacal. A densidade da urina foi medida em um refratômetro ${ }^{1}$.

Com auxílio de tiras reagentes ${ }^{2}$, determinou-se o $\mathrm{pH}$ da urina, e a presença de nitrito, de sangue e de proteína nas amostras. Nos casos em que a prova do nitrito resultava negativa, realizou-se uma segunda prova de acordo com a metodologia descrita por WENTZ (1976). Assim, daquelas amostras retirava-se cinco mililitros aos quais eram adicionadas três gotas de nitrato de potássio $\left(\mathrm{KNO}^{3}\right)$ a $5 \%$. Após um período de incubação de quatro horas à $37^{\circ} \mathrm{C}$, realizava-se novamente a pesquisa de nitrito na urina, com auxílio de tiras reagentes.

A interpretação dos resultados foi feita conforme descrito por BERNER (1978); MADEC e DAVID (1983); PERESTRELO e PERESTRELO (1988), considerando-se como positivas para infecção urinária as amostras de urina com presença de nitrito e/ou sangue.

O exame do sedimento urinário foi realizado para pesquisa quantitativa e qualitativa de

\footnotetext{
${ }^{1}$ Refratômetro Schuco®, n. ${ }^{\circ} 25276$, Japão.

2 Rapignost $₫$ Basis Screen - Behring - Alemanha
} 
Prevalência de infecção urinária e de Actinomyces suis em porcas gestantes e sua correlação com alguns...

cristais. Para obtenção do sedimento, após homogeneizar a amostra, cinco mililitros de urina eram colocados em tubo de ensaio de fundo cônico e centrifugados a 1500 rpm por cinco minutos. Em uma lâmina de microscopia, colocou-se uma gota do sedimento e procedeu-se o exame em microscópio ótico.

Do sedimento urinário obtido de acordo com a técnica acima descrita, fez-se também um esfregaço que, após fixação pelo calor, realizou-se pesquisa de $A$. suis por meio de imunofluorescência indireta (IFI). O antisoro anti-Actinomyces suis e o conjugado para IFI foram produzidos na Escola Superior de Medicina Veterinária de Hannover/Alemanha de acordo com a metodologia descrita por WENDT et al. (1993a). Utilizou-se a cepa NTC 10373 do $A$. suis para o preparo do antisoro. As diluições do antisoro e do conjugado foram de 1:150 e de 1:500, respectivamente. Das 25 granjas incluídas neste estudo, a pesquisa de $A$. suis foi realizada em apenas 23 , totalizando 1585 porcas.

Os dados obtidos foram analisados no programa estatístico Statistical Analysis System (SAS) ${ }^{3}$. Utilizando-se o procedimento para tabela de freqüência para dados categorizados "Proc Freq" do SAS, cruzaramse entre si as variáveis estudadas, sendo consideradas correlacionadas quando o quiquadrado obtido do cruzamento entre elas foi menor ou igual a 0,05.

\section{Resultados e Discussão}

A prevalência de infecção urinária entre as granjas variou de zero a $55,24 \%$, com média de $28,31 \%$. A prevalência de $A$. suis nas granjas variou de zero a $40 \%$, com média de $20,63 \%$. As taxas de prevalência de infecção urinária variaram também de acordo com o sistema de criação em que as porcas eram mantidas (TABELA 1). Nas granjas que mantinham as porcas confinadas a prevalência de infecção urinária foi de 29,54\%. Resultados semelhantes foram relatados por MADEC e DAVID (1984); PERESTRELO e PERESTRELO (1988) e SOBESTIANSKY et al. (1995). Valores de prevalência de infecção urinária maiores que $26 \%$ indicam a existência de problemas crônicos e graves na granja, onde espera-se encontrar elevada freqüência de porcas com corrimento vulvar e com problemas no puerpério e alta taxa de retorno ao cio e de morte súbita de porcas (SOBESTIANSKY e DALLA COSTA, 1995b).

\footnotetext{
${ }^{3}$ Statistical Analysis System, versão 6.03, E.U.A., 1987.
}

As granjas que mantinham as porcas ao ar livre apresentaram taxas de prevalência de infecção urinária e de $A$. suis significativamente menores do que as observadas nas granjas que as mantinham confinadas. Esses resultados comprovam as vantagens desse sistema de criação na prevenção de infecção urinária e são corroborados pelos achados de SOBESTIANSKY e DALLA COSTA (1995a) que, examinando 7 granjas que adotavam o SISCAL, encontraram porcas portadoras de $A$. suis em apenas duas delas.

Demonstrou-se claramente a habilidade do A. suis em sobreviver no trato urinário das porcas. Das 1585 fêmeas examinadas, $20,63 \%$ albergavam a bactéria em seus tratos urinários. Esse valor assemelha-se ao descrito por DEE et al. (1993) que encontraram prevalência de $A$. suis de $26 \%$; e é maior do que o encontrado por WENDT e VESPER (1992), SOBESTIANSKY e DALLA COSTA (1995a), VAZ et al. (1995) que registraram taxas de prevalência de $11,4,12,0$ e $17,0 \%$ respectivamente.

Observou-se correlação negativa entre a ocorrência de infecção urinária e a presença de $A$. suis na urina. Em outras palavras, porcas que apresentaram infecção urinária tinham menor prevalência de $A$. suis $(13,67 \%)$ do que as que não a apresentaram $(23,12 \%)$. Da mesma forma, porcas portadoras de $A$. suis, tinham menor prevalência de infecção urinária $(17,43 \%)$ do que as não portadoras $(28,62 \%)$. Apenas $3,60 \%$ das porcas eram portadoras de $A$. suis e de infecção urinária simultaneamente. Não existe subsídio na literatura para explicar a observação de correlação negativa entre infecção urinária e A. suis. Alguns autores encontraram maior prevalência de $A$. suis em porcas provenientes de granjas com problema de infecção urinária (WENDT e VESPER, 1992). Da mesma maneira, WENDT (1992) examinou 943 porcas e encontrou 108 positivas para $A$. suis, sendo que $55 \%$ destas tinham cistite, uma percentagem bem superior à encontrada no presente estudo, que foi de $17,43 \%$. De acordo com este autor, as condições para a aderência do $A$. suis na mucosa da bexiga são melhores caso haja lesão prévia provocada por bactérias pertencentes à flora fecal, deste modo, expondo camadas teciduais diferentes que possam possuir receptores para o $A$. suis. Uma hipótese que poderia explicar a correlação negativa observada, seria a de que possa existir competição entre a flora de origem fecal e o $A$. suis. A interação positiva 
entre as duas floras bacterianas passa a ocorrer a partir do momento em que a primeira provoca lesão inicial na mucosa urinária, o que permite a adesão do $A$. suis. No entanto, deve-se considerar que a presença de $A$. suis no sedimento urinário pode significar que a porca é apenas portadora, não significando necessariamente que a bactéria esteja provocando infecção urinária.

A participação do $A$. suis na patogênese da infecção pode ser demonstrada pela pesquisa de sangue na urina, pois a hematúria é um dos sinais clínicos mais importantes nas infecções urinárias provocadas por aquela bactéria (JONES, 1992; SOBESTIANSKY e WENDT, 1993). Comprovando as afirmações desses autores, no presente estudo demonstrou-se que, das 327 porcas portadoras de $A$. suis, apenas $32(7,34 \%)$ apresentaram hematúria mas, das 32 porcas que apresentaram hematúria, $75 \%$ eram portadoras de $A$. suis. Estes resultados reforçam a hipótese de que porcas podem ser portadoras sadias de $A$. suis e de que, quando apresentam hematúria, a possibilidade desta bactéria estar participando da patogênese da infecção urinária é muito grande. Cabe ressaltar que embora o $A$. suis tenha sido isolado da urina de $20,63 \%$ das porcas, apenas $3,60 \%$ delas foram positivas para infecção urinária e para $A$. suis simultaneamente e que apenas 2,02\% apresentaram hematúria. Isto demonstra que, embora o $A$. suis seja uma bactéria freqüentemente isolada do aparelho urinário de porcas, a freqüência de sua participação na patogênese das infecções urinárias nesses animais é muito pequena.

TABELA 1 - NÚMERO E PERCENTAGEM DE PORCAS PORTADORAS E NÃO PORTADORAS DE INFECÇÃO URINÁRIA (IU) OU DE Actinomyces suis, DE ACORDO COM O SISTEMA DE CRIAÇÃO ADOTADO EM 25 GRANJAS DA REGIÃO SUL DO BRASIL.

\begin{tabular}{|c|c|c|c|c|c|c|c|c|}
\hline \multirow{2}{*}{$\begin{array}{c}\text { SISTEMA } \\
\text { DE } \\
\text { CRIAÇÃO }\end{array}$} & \multicolumn{2}{|c|}{$\begin{array}{c}\text { Não portadoras } \\
\text { de IU }\end{array}$} & \multicolumn{2}{|c|}{$\begin{array}{l}\text { Portadoras } \\
\text { de IU }\end{array}$} & \multicolumn{2}{|c|}{$\begin{array}{c}\text { Não portadoras } \\
\text { de } A \text {. suis }\end{array}$} & \multicolumn{2}{|c|}{$\begin{array}{c}\text { Portadoras } \\
\text { de } A \text {. suis }\end{array}$} \\
\hline & $\mathrm{N}$ & $\%$ & $\mathrm{~N}$ & $\%$ & $\mathrm{~N}$ & $\%$ & $\mathrm{~N}$ & $\%$ \\
\hline SISCON & 1114 & 70,46 & 467 & 29,54 & 1105 & 77,76 & 316 & 22,24 \\
\hline SISCAL & 137 & 83,54 & 27 & 16,46 & 153 & 93,29 & 11 & 6,71 \\
\hline
\end{tabular}

SISCON - sistema intensivo de suínos criados confinados.

SISCAL - sistema intensivo de suínos criados ao ar livre.

Houve também correlação positiva entre as presenças de sangue e de nitrito na urina. Como os casos que apresentaram hematúria estavam freqüentemente associados à presença de $A$. suis, e como esta bactéria não transforma nitrato em nitrito, conclui-se que as infecções provocadas por ela geralmente estavam acompanhadas de flora bacteriana capaz de reduzir o nitrato em nitrito. Essa conclusão encontra respaldo nas informações de WENDT (1992), de que as infecções urinárias provocadas por $A$. suis raramente são puras, sendo na maioria dos casos associadas à uma flora mista.

A cor predominante da urina foi a amarelo claro, presente em $57,48 \%$ das amostras. Observou-se também que, das porcas portadoras de infecção urinária, 62,55\% apresentaram urina amarelo claro, e apenas $35,83 \%$ apresentaram urina amarelo escuro, contrariando as observações de SOBESTIANSKY e WENDT (1993) de que, nos casos de infecção urinária, a urina das porcas tende a apresentar uma coloração amarelo escuro.

Em relação ao aspecto, $83,15 \%$ das amostras de urina foram classificadas como turvas, sendo que para as positivas para infecção urinária, esta percentagem atingiu $90,28 \%$. Deve-se considerar que a urina de qualquer espécie animal pode turvar-se por precipitação dos sais nela eventualmente presentes ao ser deixada em repouso por certo tempo, principalmente se mantidas na geladeira ou se a temperatura ambiente estiver muito baixa (GARCIA-NAVARRO, 1996). Comprovando esta possibilidade, observou-se que das 891 amostras de urina que apresentaram cristais, $96,18 \%$ delas foram classificadas como turvas. Neste trabalho, a classificação das amostras foi feita aproximadamente 30 minutos após a retirada das mesmas das caixas isotérmicas com gelo. Tendo em vista que a temperatura ambiente geralmente encontrava-se abaixo dos $20{ }^{\circ} \mathrm{C}$, pode-se concluir que o grande número de amostras classificadas como turvas tenha sido devido a precipitação dos cristais nelas presentes.

Os tipos de cristais encontrados e a sua incidência foram semelhantes ao relatado por outros autores como MADEC (1984a) e PERESTRELO e PERESTRELO (1988) (TABELA 2). Da mesma maneira que no presente estudo, esses últimos autores também observaram maior freqüência de 
Prevalência de infecção urinária e de Actinomyces suis em porcas gestantes e sua correlação com alguns...

cristais nas urinas alcalinas. Nestas, ocorre aumento da precipitação de cristais de, particularmente, fosfato amoníacomagnesiano, que irritam a mucosa do trato urinário e criam um sítio para crescimento bacteriano (DEE, 1992). Contudo, neste estudo não se observou correlação entre as presenças de cristais e de infecção urinária, sendo muito próximos os valores de prevalência de infecção urinária nas porcas com cristalúria $(27,50 \%)$ e a nas porcas sem cristalúria $(29,10 \%)$.

TABELA 2 - DISTRIBUIÇÃO, SEGUNDO A PRESENÇA E O TIPO DE CRISTAL ENCONTRADO, DE AMOSTRAS DE URINA DE PORCAS GESTANTES.

\begin{tabular}{|c|c|c|c|c|c|c|c|c|c|c|}
\hline \multirow{3}{*}{$\begin{array}{c}\text { CRISTAIS } \\
\text { NA } \\
\text { URINA }\end{array}$} & \multicolumn{10}{|c|}{ TIPO DE CRISTAIS* } \\
\hline & \multicolumn{2}{|c|}{ FAM } & \multicolumn{2}{|c|}{ UA } & \multicolumn{2}{|c|}{$\mathrm{OC}$} & \multicolumn{2}{|c|}{ FA } & \multicolumn{2}{|c|}{ SC } \\
\hline & $\mathrm{N}$ & $\%$ & $\mathrm{~N}$ & $\%$ & $\mathrm{~N}$ & $\%$ & $\mathrm{~N}$ & $\%$ & $\mathrm{~N}$ & $\%$ \\
\hline Ausentes & 1249 & 74,0 & 1315 & 77,9 & 1321 & 78,3 & 1608 & 95,3 & 1663 & 98,6 \\
\hline Presentes & 438 & 26 & 372 & 22,1 & 366 & 21,7 & 79 & 4,7 & 24 & 1,4 \\
\hline Total & 1687 & 100 & 1687 & 100 & 1687 & 100 & 1687 & 100 & 1687 & 100 \\
\hline
\end{tabular}

${ }^{*} \mathrm{FAM}$ - fosfato amoníaco magnesiano, FA - fosfato amorfo, UA - urato amorfo, OC - oxalato de cálcio, SC Sulfato de cálcio.

O odor da urina, embora seja uma prova bastante subjetiva, pode ser utilizado como indicativo da existência de infecção urinária, uma vez que $62,37 \%$ das porcas que apresentavam urina com odor amoniacal foram positivas para infecção urinária. O odor amoniacal aparece quando existem bactérias que transformam a uréia da urina em amônia (COLES, 1989). Embora o $A$. suis também seja uma bactéria que transforme a uréia em amônia (DEE, 1992), no presente trabalho não se verificou correlação entre o odor e a presença daquela bactéria na urina.

Demonstrou-se que $29,47 \%$ das porcas apresentavam proteinúria e que houve correlação entre esta variável e a presença de infecção urinária (TABELA 3). Este resultado é semelhante ao encontrado por REIS et al.
(1992) que examinaram 2.024 porcas provenientes de granjas do Estado de Minas Gerais e encontraram $22 \%$ delas com proteinúria. Aqueles autores encontraram também uma concordância de $76 \%$ entre a presença de proteinúria e bacteriúria em níveis de $10^{5^{5}}$ bactérias $/ \mathrm{ml}$. Nos casos de infecção urinária, a proteinúria pode aparecer em conseqüência do aumento da permeabilidade glomerular presente nos casos de nefrites. Uma outra justificativa para a proteinúria seria a presença de exsudatos ou células resultantes do processo inflamatório ou de sangue (COLES, 1989). Neste sentido, observou-se correlação positiva entre hematúria e proteinúria, sendo que das 44 porcas que apresentaram hematúria, $75 \%$ apresentavam simultaneamente proteinúria.

TABELA 3 - NÚMERO E PERCENTAGEM DE PORCAS PORTADORAS E NÃO PORTADORAS DE INFECÇÃO URINÁRIA (IU) OU DE Actinomyces suis, DE ACORDO COM A PRESENÇA OU NÃO DE PROTEÍNA NA URINA.

\begin{tabular}{lcccccccc}
\hline $\begin{array}{c}\text { PROTEÍNA } \\
\text { NA URINA }\end{array}$ & \multicolumn{2}{c}{$\begin{array}{c}\text { Não portadoras } \\
\text { de IU }\end{array}$} & \multicolumn{2}{c}{$\begin{array}{c}\text { Portadoras } \\
\text { de IU }\end{array}$} & \multicolumn{2}{c}{$\begin{array}{c}\text { Não portadoras } \\
\text { de A. suis }\end{array}$} & $\begin{array}{c}\text { Portadoras } \\
\text { de } A . \text { suis }\end{array}$ \\
\cline { 2 - 10 } & $\mathrm{N}$ & $\%$ & $\mathrm{~N}$ & $\%$ & $\mathrm{~N}$ & $\%$ & $\mathrm{~N}$ & $\%$ \\
\hline Negativo & 912 & 72,96 & 318 & 64,37 & 894 & 71,12 & 225 & 68,81 \\
$30 \mathrm{mg} / \mathrm{dl}$ & 294 & 23,52 & 135 & 27,33 & 305 & 24,26 & 81 & 24,77 \\
$100 \mathrm{mg} / \mathrm{dl}$ & 37 & 2,96 & 29 & 5,87 & 49 & 3,90 & 13 & 3,98 \\
$500 \mathrm{mg} / \mathrm{dl}$ & 7 & 0,56 & 12 & 2,43 & 9 & 0,72 & 8 & 2,45 \\
TOTAL & 1250 & 100 & 494 & 100 & 1257 & 100 & 327 & 100 \\
\hline
\end{tabular}

O valor médio de $\mathrm{pH}$ da urina de todas porcas examinadas foi de 6,51 $\pm 0,98$, sendo que $71,96 \%$ das porcas apresentaram valores entre 6,0 e 7,5 (TABELA 4). Estes valores estão de acordo com os citados na literatura (JONES, 1992; DEE, 1992). Considerando-se isoladamente as porcas normais e com infecção urinária, os valores de $\mathrm{pH}$ foram de, respectivamente, $6,50 \pm 0,96$ e 6,53 $\pm 1,04$. Não se observou correlação entre a presença de infecção urinária e $\mathrm{o} \mathrm{pH}$ da urina. Corroborando os resultados obtidos no presente estudo, CARR e WALTON (1992), examinando 52 porcas com bacteriúria, encontraram valores médios de $\mathrm{pH}$ de 7,0. Contudo, é geralmente aceito que, nos casos de infecção urinária, espera-se encontrar urina alcalina, pois a flora bacteriana localizada nas vias urinárias transforma a uréia em amônia, provocando alcalinização (COLES, 1989). De 
acordo com SOBESTIANSKY e WENDT (1993), nos casos de infecção urinária, o pH da urina varia entre 8,0 e 9,0 e, num trabalho feito por MADEC (1984b), observou-se uma maior percentagem de urina com sangue e proteína, quando o $\mathrm{pH}$ era maior que 8,0 . Outros autores consideram também que, quando o pH da urina é alcalino, as chances do animal desenvolver infecção urinária é maior (SOBESTIANSKY et al., 1992). Contudo, deve-se ressaltar que a maioria das infecções urinárias é provocada pela $E$. coli (BERNER, 1980; MADEC e DAVID 1983) e que, na maioria da vezes, estas infecções são puras (BERNER, 1978). Tendo em vista que a $E$. coli não produz urease e, conseqüentemente, não transforma a uréia em amônia (QUINN et al., 1994), é possível que não ocorra alcalinização da urina em infecções produzidas por esta bactéria.

Por outro lado, apesar do $A$. suis produzir urease e, assim, aumentar a alcalinidade da urina pela transformação da uréia em amônia (DEE, 1992), tampouco foi possível demonstrar correlação positiva entre os valores de $\mathrm{pH}$ e a presença daquela bactéria nas amostras examinadas. Enquanto em casos comprovados de infecção pelo $A$. suis, $\mathrm{o} \mathrm{pH}$ da urina pode chegar a 8,5 (DEE, 1991), não existem referências na literatura especializada quanto aos valores de $\mathrm{pH}$ da urina para porcas portadoras sadias de $A$. suis.

TABELA 4 - NÚMERO E PERCENTAGEM DE PORCAS PORTADORAS E NÃO PORTADORAS DE INFECÇÃO URINÁRIA (IU) OU DE Actinomyces suis, DE ACORDO COM O pH URINÁRIO.

\begin{tabular}{|c|c|c|c|c|c|c|c|c|}
\hline \multirow[t]{2}{*}{$\begin{array}{c}\mathrm{pH} \\
\text { URINÁRIO }\end{array}$} & \multicolumn{2}{|c|}{$\begin{array}{c}\text { Não portadoras } \\
\text { de IU }\end{array}$} & \multicolumn{2}{|c|}{$\begin{array}{c}\text { Portadoras } \\
\text { de IU }\end{array}$} & \multicolumn{2}{|c|}{$\begin{array}{c}\text { Não portadoras } \\
\text { de A. suis }\end{array}$} & \multicolumn{2}{|c|}{$\begin{array}{c}\text { Portadoras } \\
\text { de A. suis }\end{array}$} \\
\hline & $\mathrm{N}$ & $\%$ & $\mathrm{~N}$ & $\%$ & $\mathrm{~N}$ & $\%$ & $\mathrm{~N}$ & $\%$ \\
\hline$<6,1$ & 617 & 49,32 & 253 & 51,21 & 612 & 48,65 & 163 & 49,85 \\
\hline 6,1 I I, I,3 & 441 & 35,25 & 153 & 30,97 & 437 & 34,74 & 113 & 34,56 \\
\hline$>7,3$ & 193 & 15,43 & 88 & 17,81 & 209 & 16,61 & 51 & 15,60 \\
\hline TOTAL & 1251 & 100 & 494 & 100 & 1258 & 100 & 327 & 100 \\
\hline Valor médio & \multicolumn{2}{|c|}{$6,50 \pm 0,96$} & \multicolumn{2}{|c|}{$6,53 \pm 1,04$} & \multicolumn{2}{|c|}{$6,50 \pm 0,97$} & \multicolumn{2}{|c|}{$6,49 \pm 1,02$} \\
\hline
\end{tabular}

Não se observou correlação entre a densidade da urina e infecção urinária. No geral, a densidade média foi de 1016, não diferindo entre as porcas com ou sem infecção. Evidentemente existe correlação entre ingestão diária de água e a densidade da urina da primeira micção matinal. Assim, quando a ingestão de água é suficiente, insuficiente ou se encontra em um limite crítico, a densidade da urina é menor que 1008, maior que 1012 e entre 1008 e 1012 respectivamente (SOBESTIANSKY et al., 1992). Levando-se em consideração esta relação, poder-se-ia concluir que das porcas incluídas neste trabalho, apenas $24,58 \%$ apresentavam ingestão suficiente de água. Contudo, JOURQUIN et al. (1992) encontraram densidade urinária de 1015 para porcas com ingestão diária de água acima de 15 litros por dia, volume mínimo recomendado para gestantes (MADEC, 1984b). Assim, os valores maiores que 1012 observados no presente trabalho podem ser considerados como esperados e dentro da normalidade.

\section{Conclusões}

Com base nos resultados obtidos no presente estudo, pode-se concluir que:
- A prevalência de infecção urinária em porcas gestantes mantidas em confinamento situa-se em níveis considerados graves. Por outro lado, quando as porcas são mantidas ao ar livre, a prevalência é significativamente menor.

- A bactéria $A$. suis pode sobreviver no trato urinário de porcas sadias, sem causar infecção urinária ou mesmo predispô-las à ela.

- Existe correlação negativa entre a ocorrência de infecção urinária e a presença de $A$. suis no trato urinário das porcas.

- A hematúria pode ser considerada um indicativo confiável do envolvimento do $A$. suis nos casos de infecção urinária em porcas, uma vez que existe correlação entre a ocorrência de hematúria e a presença dessa bactéria na urina de porcas gestantes.

- A cor da urina não deve ser considerada como um parâmetro indicador da presença ou não de infecção urinária em porcas, uma vez que a cor predominante de sua urina é a amarelo claro, mesmo naqueles casos que apresentam infecção urinária.

- A turbidez na urina de porcas é um achado freqüente e que, na grande maioria dos casos, deve-se à precipitação de cristais na amostra e não à presença de infecção ou de $A$. suis. 
Prevalência de infecção urinária e de Actinomyces suis em porcas gestantes e sua correlação com alguns...

- A densidade normal da urina de porcas é de 1016, não existindo correlação entre ela e a presença de infecção urinária ou de $A$. suis.

- O pH normal da urina de porcas é de 6,5, valor que é encontrado tanto em porcas normais quanto nas portadoras de infecção urinária ou de $A$. suis.

- As porcas com cristalúria não apresentam maior prevalência de infecção urinária.

\section{REFERÊNCIAS BIBLIOGRÁFICAS}

BERNER, H. Die Harnwegsinfektionen beim Schwein. München, 1978, 427p. Tese (Habilitationsschrift) - Tierärztliche Universität München.

BERNER, $\mathrm{H}$. The effect of chronic urinary tract infection in the sow on renal function. In: INTERNATIONAL PIG VETERINARY SOCIETY CONGRESS, 6, Copenhagen, 1980. Proceedings... Copenhagen: IPVS, 1980, p.137.

CARR, J.; WALTON, J. R. Characteristics of plasma and urine from normal adult swine and changes found in sows with either asymptomatic bacteriuria or cystitis and pyelonephritis. In: INTERNATIONAL PIG VETERINARY SOCIETY CONGRESS, 12, The Hague, 1992. Proceedings... The Hague, 1992, p. 263.

COLES, E.H. Prueblas de funcionamento renal. In: COLES, E.H. Diagnóstico y patologia en veterinária. México: Interamericana, 4 ed. 1989, p.175-206.

DEE, S. A. Diagnosing and controlling urinary tract infections caused by Eubacterium suis in swine. Veterinary Medicine, v.86, n.2, p.231-238, 1991.

DEE, S.A. Porcine Urogenital Disease. Veterinary Clinics of North America: Food Animal Practice, v.8, n.3, p.641-660, 1992.

DEE, S.A.; CARLSON, A.R.; COREY, M.M. New observations on the epidemiology of Eubacterium suis. Veterinary Clinics of North America: Food Animal Practice, v.15, n.2, p.345-348, 1993.

GARCIA-NAVARRO, C.E.K. Manual de urinálise. São Paulo, Varela, 1996, 169 p.

JONES, J.E.T. Urinary system. In: LEMAN, A.D.; STRAW, B.E.; MENGELING, W. L. et al. Diseases of swine. London, Wolfe, 7. ed. 1992, p.217-222.

JOURQUIN, J.; SEYNAEVE, M.; DE WILDE, R.O. The influence of the spontaneous water intake on the urine composition and urological parameters in gestating and lactating gilts and sows. In: INTERNATIONAL PIG VETERINARY SOCIETY CONGRESS, 12, 1992. The Hague. Proceedings... The Hague: IPVS, 1992, p. 605.

MADEC, F. Analyse des causes de mortalité des truies en cours de période d'éllevage. Recueil de Médecine Vétérinaire, v.160, n.4, p.329-335, 1984a.
MADEC, F. Urinary disorders in intensive pig herds. Pig News and Information, v.5, n.2, p.89-93, 1984b.

MADEC, F.; DAVID, F. Les troubles urinaires des troupeaux de truies: diagnostic, incidence et circonstances d'apparition. Journées de Recherche Porcine en France, v.15, p.431-446, 1983.

MADEC, F.; DAVID, F. Urinary problems in sow herds. In: INTERNATIONAL PIG VETERINARY SOCIETY CONGRESS, 8, 1984, Ghent. Proceedings... Ghent: IPVS, 1984 , p. 148.

PERESTRELO, R.; PERESTRELO, H. Transtornos urinarios en las explotaciones intensivas de cerdos en Portugal. Anaporc, v.68, p.62-71, 1988.

QUINN, P.J.; CARTER, M.E.; MARKEY, B.K.; CARTER, G.R. Clinical Veterinary Microbiology. London, Wolfe, 1994, p.209236.

REIS, R.; NAKAJIMA, M.; NASCIMENTO, E.F. Infecções urinárias em porcas. Arquivo Brasileiro de Medicina Veterinária e Zootecnia, v.44, n.5, p.363376, 1992.

SOBESTIANSKY, J.; BARCELLOS, D.; MORES, N. Clínica e patologia suína. Goiânia: J. Sobestiansky, 2 ed. 1999, 464p.

SOBESTIANSKY, J; DALLA COSTA, O.A. Infecção urinária na fêmea em produção: resultados preliminares de estudo de prevalência de Eubacterium suis. In: CONGRESSO BRASILEIRO DE VETERINÁRIOS ESPECIALISTAS EM SUÍNOS, 7, 1995, Blumenau. Anais... Blumenau: ABRAVES, $1995 a$, p.118.

SOBESTIANSKY, J.; DALLA COSTA, O.A. Infecção urinária na fêmea em produção: sugestão para interpretação de resultados de taxa de prevalência. In: CONGRESSO BRASILEIRO DE VETERINÁRIOS ESPECIALISTAS EM SUÍNOS, 7, 1995, Blumenau. Anais... Blumenau, ABRAVES, 1995b, p.121.

SOBESTIANSKY, J.; MORES. N.; PERESTRELO, R. Infecções urinárias na fêmea suína. Circular Técnica. Concórdia, EMBRAPA-CNPSA, v.11, p.7-49, 1992.

SOBESTIANSKY, J.; PERUZZO, B.F.; DALLA COSTA, O.A.; ALBERTON, G. Infecção urinária na fêmea em produção: ocorrência em granjas com queda da eficiência reprodutiva. In: CONGRESSO BRASILEIRO DE VETERINÁRIOS ESPECIALISTAS EM SUÍNOS, 7, 1995, Blumenau. Anais... Blumenau, ABRAVES, 1995, p. 68.

SOBESTIANSKY, J.; WENDT, M. Infecções urinárias na fêmea suína: epidemiologia, sintomatologia, diagnóstico e controle. In: CONGRESSO BRASILEIRO DE VETERINÁRIOS ESPECIALISTAS EM SUÍNOS, 6, 1993, Goiânia. Anais... Goiânia, ABRAVES, 1993, p. 51-63. 
VAZ, E.K.; SOBESTIANSKY, J.; BRUM, S.; FRANKE, M.R. Prevalência de Eubacterium suis no Planalto Catarinense. In: CONGRESSO BRASILEIRO DE VETERINÁRIOS ESPECIALISTAS EM SUIINOS, 7 1995, Blumenau. Anais... Blumenau , ABRAVES, 1995, p.119.

WENDT, M. Untersuchungen zur Diagnostik und zur Charakterisierung von Harnwegsinfektionen der Sau unter besonderer Berucksichtigung von Eubacterium suis. Hannover, 1992. 242 p., Tese (Habilitationsschrift) - Tierärztliche Hochschule Hannover.

WENDT, M.; SOBESTIANSKY, J.; AMTSBERG, G. Infecções urinárias em suínos: Identificação de Eubacterium suis por imunofluorescência directa. Revista Portuguesa de Ciências Veterinárias, v.88, n.508, p.176-180, 1993a.
WENDT, M.; SOBESTIANSKY, J.; BOLLWAHN, W. Infecções urinárias em suínos: estudo sobre o tratamento de machos infectados por Eubacterium suis. Revista Portuguesa de Ciências Veterinárias, v.88, n.508, p.182-185, 1993b.

WENDT, M.; VESPER, C. Occurrence of Eubacterium suis in breeding herds. In: INTERNATIONAL PIG VETERINARY SOCIETY CONGRESS, 12, 1992, The Hague. Proceedings... The Hague, IPVS, 1992, p.349.

WENTZ, I. Untersuchungen des Harn und Geschlechtsapparat bei Sauen nach Schnittentbindungen mit Berücksichtigung klinicher und bakteriologischer Aspekte. Hannover, 1976, 48 p., Dissertation Tierärztliche Hochschule Hannover. 